EVIDENCE BASED PUBLIC HEALTH POLICY AND PRACTICE

\title{
SARS related preventive and risk behaviours practised by Hong Kong-mainland China cross border travellers during the outbreak of the SARS epidemic in Hong Kong
}

\author{
Joseph T F Lau, Xilin Yang, H Y Tsui, Ellie Pang
}

J Epidemiol Community Health 2004;58:988-996. doi: 10.1136/jech.2003.017483

See end of article for authors' affiliations

Correspondence to: Dr J T F Lau, Centre for Epidemiology and Biostatistics, 5/F, School of Public Health, Prince of Wales Hospital, Shatin, NT, Hong Kong; jlau@cuhk.edu.hk

Accepted for publication 26 April 2004

\begin{abstract}
Objectives: To investigate patterns of behaviours and attitudes related to SARS prevention in the Hong Kong cross border traveller population.

Settings: A survey was carried out at the Hong Kong-China cross border checkpoint in the middle of the epidemic.

Participants: A total of 839 Hong Kong adult residents returning to Hong Kong from mainland China were surveyed.

Main outcome measures: Practice of preventive measures and relevant behaviours and attitudes.

Results: Around $40 \%$ of the respondents were using masks all or most of the time in public places or washing their hands frequently (>10 times per day) and about one third avoided visiting crowded places in mainland China. Such figures were however lower than those practised by the general public in Hong Kong. SARS related perceptions, such as perceived risk of transmission and efficacy, etc, were associated with mask use and not visiting crowded places, but not with hand washing, which was associated with duration of stay. Gender differences were also observed. Around $70 \%$ of the travellers would have delayed medical consultation for influenza-like illness in China; $12.7 \%$ would not wear masks during such episodes of illness. Furthermore, about $30 \%$ of the respondents used to wear masks in Hong Kong but not in mainland China.

Conclusions: The findings have implications on cross border prevention of SARS. It seems that those travelling during the SARS epidemic were a "self selected" group, and they were using less preventive measures. Special attention and intervention need to be provided to travellers to prevent a second wave cross border transmission of the disease.
\end{abstract}

$\mathrm{T}$ he number of SARS cases reported in Hong Kong and in mainland China ( 1755 and 5327 respectively) was $84.1 \%$ of the global figure. ${ }^{1}$ There were 300 and 349 deaths in the two places respectively, which was $70.9 \%$ of the global total. Around November 2002, a number of cases with SARSlike symptoms were reported for the first time in Guangdong, China. The first major outbreak in Hong Kong was caused by a visitor coming from Guangzhou (about 150 kilometres from Hong Kong), who stayed in the Hotel Metropole. ${ }^{2}$ The coronavirus has been found in some animals that are regularly consumed as food by people in Guangdong. ${ }^{3}$ Some infected Hong Kong residents travelled to mainland China and spread the disease to others in mainland China as well. Moreover, a matched case-control study shown that visiting mainland China was a significant risk factor for SARS transmission. ${ }^{4}$ There was therefore a strong linkage between the SARS epidemic in Hong Kong and that in mainland China. During the outbreak of the SARS epidemic, $79.6 \%$ of the Hong Kong residents perceived a high risk of contracting SARS when travelling to Guangdong, China and $70.8 \%$ of the respondents avoided travelling to mainland China. ${ }^{5}$

In 2002, 55648000 person trips were made by the Hong Kong residents to mainland China, which was much higher than the 2001 figure $^{6}$; the number of mainland China people visiting Hong Kong had also increased sharply (from 4449000 in 1997 to 6825000 in 2002). ${ }^{7}$ As a result of recent relaxation of relevant policies, a further dramatic increase has been observed by 43.4\% from August 2002 to August 2003. ${ }^{8}$ From 16 December 2003 to 31 January 2004, four new confirmed SARS cases were reported in the Guangdong province, China. ${ }^{9}$ That raises an alarm and shows the urgency for cross border prevention of SARS between Hong Kong and mainland China. The future scenarios of SARS in Hong Kong and in mainland China would not be separable.

As some major outbreaks had occurred as a result of the late identification by the surveillance system, it is imperative that SARS cases be detected as soon as possible, to minimise the number of contacts from the contagious person. ${ }^{10}$ It is also important to understand the characteristics of these travellers who were travelling in the middle of the outbreak. Some special risks may be identified and some special strategies may be required to tackle such issues. The study aims to investigate the prevalence of preventive behaviours practised by cross border travellers as well as behaviours/ attitudes that were not conducive to effective SARS prevention. Factors that were associated with such behaviours and perceptions were also investigated.

\section{METHODS}

\section{Respondents}

The study population comprised Hong Kong Chinese residents of 18-60 years of age, who were travelling back to Hong Kong from mainland China via Shenzhen. Respondents were interviewed at the exit hall of the Lo Wu custom office, an important checkpoint between Hong Kong and Shenzhen. A structured questionnaire and systematic sampling methods were used. This study design has been used in other similar studies. ${ }^{11}{ }^{12}$ The interviews were conducted from 900 am to 700 pm between 26 April 2003 and 30 April 2003. Each interview took about five minutes to complete. The outbreak of the SARS epidemic in Hong Kong occurred between 
11 March $2003^{13}$ and 11 June 2003. ${ }^{14}$ The World Health Organisation's travel advice against visiting Hong Kong was effective from 2 April $2003^{15}$ to 23 May 2003. ${ }^{16}$ The study was therefore carried out in the middle of the epidemic in Hong Kong.

A total of 1664 eligible respondents were invited to join the study. They were assured that the study was anonymous and confidential and 839 completed the questionnaire. The response rate, defined as the number completing the questionnaire (839) divided by the number of eligible respondents approached (1664), was $50.4 \%$. The ethics was approved by the ethics committee, the Chinese University of Hong Kong and verbal consent was obtained from all the participants.

\section{Measurements}

The questionnaire collected information on: (1) demographic and background characteristics, (2) general SARS related preventive behaviours and attitudes, (3) risk behaviours/ attitudes: whether or not going to see a local doctor if having influenza-like symptoms at the destination in mainland China, whether or not wearing masks in public places in mainland China if having influenza-like symptoms in mainland China, using masks in Hong Kong but not in mainland China, and (4) SARS related perceptions, including perceived risk of Hong Kong residents contracting SARS in different places in mainland China, perceived risk of contracting SARS, perceived efficacy of mask wearing for SARS prevention, and perceived fatality of SARS.

\section{Statistical analyses}

Differences in proportions were compared using the $\chi^{2}$ test. Odds ratios were firstly derived, from univariate logistic regression models. The univariately significant variables were then entered into the multivariate forward stepwise logistic regression analysis. SPSS for Windows Release 11.0.1 (SPSS, Chicago, USA) was used to analyse the data and $\mathrm{p}$ values $<0.05$ were considered as significant.

\section{RESULTS}

\section{Background characteristics}

Of a total 839 respondents, $666(79.4 \%)$ were male and 173 $(20.6 \%)$ were female. Female respondents tended to be younger, less educated, and less likely to be currently married than male respondents (table 1). For the current trip, over $75 \%$ of the respondents had stayed overnight in mainland China and men were more likely to do so than women (table 1). Around $65.8 \%$ of the male and $74.0 \%$ of female respondents visited Shenzhen during the trip. Less than $10 \%$ of the respondents visited Guangzhou and other provinces of mainland China (6.9\% and $4.4 \%$, respectively). Male respondents had more frequently made trips to mainland China in the past month than their female counterparts (table 1).

\section{General SARS related behaviours and attitudes}

Up to $67.3 \%$ of the male and $78.8 \%$ of the female respondents were using masks in public places in Hong Kong all or most of the time in the past two weeks (table 1). Not many respondents found it difficult to buy masks in Shenzhen ( $5.5 \%$ for male and $6.9 \%$ for female respondents, $\mathrm{p}=0.530$ ) or in other parts of mainland China $(12.5 \%$ and $17.0 \%$ for male and female respondents, respectively, $\mathrm{p}=0.162$ ). Almost $30 \%$ of respondents perceived mask wearing to be highly efficacious for SARS prevention $(27.1 \%$ for male and $35.8 \%$ for female respondents). About $27 \%, 57 \%$, and $42 \%$ of the respondents believed that there was a high/very high risk for Hong Kong residents to contract SARS in Shenzhen, Guangzhou or in other places in mainland China $(23.5 \%$, $47.1 \%$, and $61.3 \%$ respectively for male respondents and $40.7 \%, 70.4 \%$, and $44.1 \%$ respectively for female respondents,

Table 1 Background characteristics of respondents

\begin{tabular}{|c|c|c|c|c|}
\hline & Male \% (n) & Female \% (n) & Total \% (n) & p Values* \\
\hline Age $(y)$ & & & & $<0.001$ \\
\hline $18-29$ & $11.1(74)$ & $27.9(48)$ & $14.6(122)$ & \\
\hline $30-44$ & $54.5(363)$ & $61.0(105)$ & $55.8(468)$ & \\
\hline $45-60$ & $34.4(229)$ & 11.0 (19) & 29.6 (248) & \\
\hline \multicolumn{4}{|l|}{ Education attainment } & 0.005 \\
\hline$\leqslant 9$ years & 22.7 (149) & $30.5(51)$ & $24.3(200)$ & \\
\hline $10-11$ years & $25.3(166)$ & $30.5(51)$ & $26.3(217)$ & \\
\hline $12-13$ years & $21.0(138)$ & $21.0(35)$ & $21.0(273)$ & \\
\hline$>$ College or university & $31.1(204)$ & $18.0(30)$ & $28.4(234)$ & \\
\hline \multicolumn{4}{|l|}{ Marital status } & 0.002 \\
\hline Married & $74.5(488)$ & $61.3(98)$ & $71.9(586)$ & \\
\hline Single & $21.6(142)$ & $29.9(50)$ & 23.3 (192) & \\
\hline Separated/divorced/widowed & $3.8(12)$ & 7.5 (12) & $4.5(37)$ & \\
\hline \multicolumn{4}{|l|}{$\begin{array}{l}\text { Duration of stay in the travel } \\
\text { destination (number of nights) }\end{array}$} & $<0.001$ \\
\hline Day trip & $18.5(122)$ & $42.9(73)$ & $23.5(195)$ & \\
\hline $1-7$ nights & $69.1(457)$ & $44.1(75)$ & $64.0(532)$ & \\
\hline 8 nights or more & $12.4(82)$ & $12.9(22)$ & $12.5(104)$ & \\
\hline \multicolumn{5}{|l|}{ Destination of the tript } \\
\hline Shenzhen & $65.8(438)$ & $74.0(128)$ & $67.5(566)$ & 0.040 \\
\hline Guangzhou & $7.1(47)$ & 6.4 (11) & $6.9(58)$ & 0.747 \\
\hline Other Guangdong cities & $28.5(190)$ & $17.9(31)$ & $26.3(221)$ & 0.005 \\
\hline Other provinces & $4.2(28)$ & $5.2(9)$ & $4.4(37)$ & 0.569 \\
\hline \multirow{2}{*}{\multicolumn{4}{|c|}{$\begin{array}{l}\text { Number of trips to China } \\
\text { in the past month }\end{array}$}} & $<0.001$ \\
\hline & & & & \\
\hline 1 & $12.5(100)$ & $43.6(75)$ & $21.0(175)$ & \\
\hline $2-3$ & $24.8(164)$ & $26.2(45)$ & 25.1 (209) & \\
\hline $4-10$ & $38.3(253)$ & $19.8(34)$ & $34.5(287)$ & \\
\hline$>10$ & $21.7(143)$ & $10.5(18)$ & $19.4(161)$ & \\
\hline \multirow{2}{*}{\multicolumn{4}{|c|}{$\begin{array}{l}\text { Frequency of wearing masks } \\
\text { in public places in Hong Kong }\end{array}$}} & 0.005 \\
\hline & & & & \\
\hline $\begin{array}{l}\text { Occasional/never } \\
\text { All/most of the time }\end{array}$ & $32.7(195)$ & $\begin{array}{l}21.2(33) \\
78.8(123)\end{array}$ & $\begin{array}{l}30.3(228) \\
697(524)\end{array}$ & \\
\hline All/most of the time & $67.3(401)$ & & & \\
\hline
\end{tabular}


Table 2 Public health behaviours for SARS prevention practised in mainland China (prevalence and univariate analysis)

\begin{tabular}{|c|c|c|c|c|c|c|}
\hline & \multicolumn{2}{|c|}{ Wearing masks in mainland China } & \multicolumn{2}{|c|}{$\begin{array}{l}\text { Frequency of washing hands in } \\
\text { mainland China }\end{array}$} & \multicolumn{2}{|c|}{$\begin{array}{l}\text { Avoid visiting crowded places in } \\
\text { mainland China }\end{array}$} \\
\hline & $\%$ & $\mathrm{OR}_{\mathrm{u}}{ }^{*}$ & $\%$ & $\mathrm{OR}_{\mathrm{ut}}$ & $\%$ & $\mathrm{OR}_{\mathrm{u}} \ddagger$ \\
\hline All & 37.2 & & 43.0 & & 69.1 & \\
\hline \multicolumn{7}{|l|}{ Gender } \\
\hline Male & 33.6 & 1.0 & 40.3 & 1.0 & 69.3 & 1.0 \\
\hline $\begin{array}{l}\text { Female } \\
\text { p Value }\end{array}$ & 50.9 & $\begin{array}{l}2.05(1.46 \text { to } 2.87) \\
<0.001\end{array}$ & 53.6 & $\begin{array}{l}1.71(1.22 \text { to } 2.41) \\
0.002\end{array}$ & 68.0 & $\begin{array}{l}0.94(0.66 \text { to } 1.35) \\
0.746\end{array}$ \\
\hline \multicolumn{7}{|l|}{ Age group } \\
\hline $18-29$ & 42.0 & 1.0 & 48.3 & 1.0 & 61.7 & 1.0 \\
\hline $30-44$ & 36.5 & $0.86(0.57$ to 1.29$)$ & 44.6 & $0.86(0.58$ to 1.29$)$ & 69.9 & $1.44(0.95$ to 2.19$)$ \\
\hline $45-60$ & 36.7 & 0.86 (0.55 to 1.35$)$ & 37.3 & $0.64(0.41$ to 0.99$)$ & 71.1 & 1.53 (0.97 to 2.43$)$ \\
\hline p value & & 0.747 & & 0.078 & & 0.158 \\
\hline \multicolumn{7}{|l|}{ Marital status } \\
\hline Married & 35.6 & 1.0 & 44.5 & 1.0 & 70.6 & 1.0 \\
\hline Single & 39.6 & 1.18 (0.85 to 1.66$)$ & 39.7 & 0.82 (0.59 to 1.15 ) & 64.6 & 0.76 (0.54 to 1.07 ) \\
\hline Separated/divorced/widowed & 37.8 & 1.10 (0.55 to 2.18$)$ & 32.4 & 0.650 (0.30 to 1.22$)$ & 67.6 & $0.87(0.43$ to 1.77$)$ \\
\hline \multicolumn{7}{|l|}{ Education attainment } \\
\hline$\leqslant 9$ years & 33.0 & 1.0 & 45.5 & 1.0 & 63.0 & 1.0 \\
\hline $10-11$ years & 35.9 & 1.14 (0.76 to 1.71$)$ & 40.9 & 0.83 (0.56 to 1.23 ) & 68.7 & $1.29(0.86$ to 1.93$)$ \\
\hline $12-13$ years & 36.4 & $1.16(0.76$ to 1.78$)$ & 47.0 & $1.07(0.71$ to 1.61$)$ & 71.5 & $1.47(0.95$ to 2.29$)$ \\
\hline College or university & 40.5 & 1.38 (0.93 to 2.05 ) & 39.7 & $0.79(0.54$ to 1.16$)$ & 73.1 & $1.59(1.07$ to 2.40$)$ \\
\hline $\mathrm{p}$ Value & & 0.443 & & 0.388 & & 0.128 \\
\hline \multicolumn{7}{|l|}{$\begin{array}{l}\text { Duration of stay in the travel } \\
\text { destination (number of nights) }\end{array}$} \\
\hline Day trip & 57.9 & 1.0 & 34.0 & 1.0 & 62.0 & 1.0 \\
\hline $1-7$ & 32.5 & $0.35(0.25$ to 0.49$)$ & 44.2 & 1.53 (1.08 to 2.17$)$ & 73.3 & $1.67(1.19$ to 2.39$)$ \\
\hline$>8$ & 24.0 & $0.23(0.14$ to 0.39$)$ & 52.0 & $2.10(1.28$ to 3.43$)$ & 62.1 & 1.01 (0.62 to 1.65 ) \\
\hline $\mathrm{p}$ Value & & $<0.001$ & & 0.008 & & 0.004 \\
\hline \multicolumn{7}{|l|}{ Travelled to Shenzhen } \\
\hline Yes & 40.1 & 1.48 (1.09 to 2.01$)$ & 41.2 & 0.80 (0.60 to 1.07$)$ & 66.1 & $0.64(0.46$ to 0.89$)$ \\
\hline No & 31.8 & 1.0 & 46.7 & 1.0 & 75.3 & 1.0 \\
\hline \multirow{2}{*}{\multicolumn{7}{|c|}{ Travelled to Guangzhou }} \\
\hline & & & & & & \\
\hline Yes & 29.3 & 0.68 (0.38 to 1.23 ) & 57.1 & $1.84(1.07$ to 3.19$)$ & 76.8 & 1.52 (0.80 to 2.88$)$ \\
\hline No & 37.7 & 1.0 & 42.0 & 1.0 & 68.5 & 1.0 \\
\hline$p$ value & & 0.203 & & 0.029 & & 0.199 \\
\hline Travelled to other Guangdong & & & & & & \\
\hline Yes & 33.0 & $0.78(0.57$ to 1.08$)$ & 46.1 & 1.19 (0.87 to 1.63 ) & 75.6 & 1.54 (1.09 to 2.19$)$ \\
\hline No & 38.6 & & 41.9 & & 66.7 & \\
\hline $\mathrm{p}$ Value & & 0.140 & & 0.276 & & 0.015 \\
\hline Travelled to other provinces & & & & & & \\
\hline Yes & 24.3 & $0.53(0.25$ to 1.14$)$ & 55.6 & 1.70 (0.87 to 3.32$)$ & 67.6 & 0.93 (0.46 to 1.88 ) \\
\hline No & 37.8 & & 42.4 & & 69.1 & \\
\hline $\mathrm{p}$ Value & & 0.105 & & 0.123 & & 0.839 \\
\hline Number of trips to mainland & & & & & & \\
\hline China in past month & & & & & & \\
\hline 1 trip & 38.9 & 1.0 & 46.2 & 1.0 & 62.2 & 1.0 \\
\hline $2-3$ & 40.7 & $1.08(0.72$ to 1.63$)$ & 43.9 & 0.91 (0.61 to 1.38$)$ & 64.6 & $1.11(0.73$ to 1.69$)$ \\
\hline $4-10$ & 32.1 & $0.74(0.50$ to 1.10$)$ & 39.6 & 0.76 (0.52 to 1.12 ) & 76.6 & $1.99(1.32$ to 3.00$)$ \\
\hline$>10$ & 39.6 & $1.03(1.67$ to 1.67$)$ & 44.6 & 0.94 (0.61 to 1.45$)$ & 70.0 & 1.42 (0.90 to 2.24$)$ \\
\hline$p$ Value & & 0.187 & & 0.519 & & 0.004 \\
\hline $\begin{array}{l}\text { Frequency of wearing masks } \\
\text { in Hong Kong }\end{array}$ & & & & & & \\
\hline Occasional/never & 8.8 & 1.0 & 38.2 & 1.0 & 57.7 & 1.0 \\
\hline All/most of the time & 51.3 & 10.97 (6.73 to 17.91$)$ & 43.3 & 1.24 (0.90 to 1.70$)$ & 75.3 & $2.23(1.60$ to 3.11$)$ \\
\hline $\mathrm{p}$ Value & & $<0.001$ & & 0.196 & & $<0.001$ \\
\hline Reasons for mask wearing & & & & & & \\
\hline in mainland China & & & & & & \\
\hline To protect oneself & 38.6 & 1.0 & 41.8 & 1.0 & 65.8 & 1.0 \\
\hline To protect others & 21.6 & $0.44(0.26$ to 0.75$)$ & 43.7 & 1.08 (0.68 to 1.73 ) & 63.1 & 0.89 (0.55 to 1.44$)$ \\
\hline Both & 42.2 & $1.16(0.84$ to 1.60$)$ & 43.0 & 1.05 (0.76 to 1.45 ) & 74.6 & $1.52(1.08$ to 2.15$)$ \\
\hline$p$ Value & & 0.001 & & 0.931 & & 0.013 \\
\hline Difficulty in buying masks in $\mathrm{S}$ & & & & & & \\
\hline Not difficult/not diffficult at all & 35.6 & 1.0 & 42.9 & 1.0 & 69.8 & 1.0 \\
\hline $\begin{array}{l}\text { Moderately difficult/difficult/ } \\
\text { very difficult }\end{array}$ & 37.2 & $1.07(0.57$ to 2.03$)$ & 41.9 & $0.96(0.51$ to 1.79$)$ & 74.4 & 1.26 (0.62 to 2.54$)$ \\
\hline $\mathrm{p}$ Value & & 0.834 & & 0.890 & & 0.524 \\
\hline $\begin{array}{l}\text { Difficulty in buying masks in } \\
\text { other places }\end{array}$ & & & & & & \\
\hline Not difficult/not difficult at all & 35.6 & 1.0 & 42.2 & 1.0 & 68.6 & 1.0 \\
\hline Moderately difficult/difficult/ & 37.1 & $1.07(0.69$ to 1.67$)$ & 45.8 & $1.16(0.75$ to 1.79$)$ & 75.3 & 1.39 (0.85 to 2.28$)$ \\
\hline p Value & & 0.769 & & 0.504 & & 0.186 \\
\hline $\begin{array}{l}\text { Perceived efficacy of wearing } \\
\text { masks for prevention of SARS }\end{array}$ & & & & & & \\
\hline Moderate/low/very low & 31.0 & 1.0 & 43.8 & 1.0 & 65.7 & 1.0 \\
\hline High/very high & 49.1 & 2.15 (1.57 to 2.94$)$ & 41.2 & 0.90 (0.66 to 1.23 ) & 78.9 & 1.96 (1.36 to 2.82$)$ \\
\hline$p$ Value & & $<0.001$ & & 0.508 & & $<0.001$ \\
\hline
\end{tabular}


Table 2 Continued

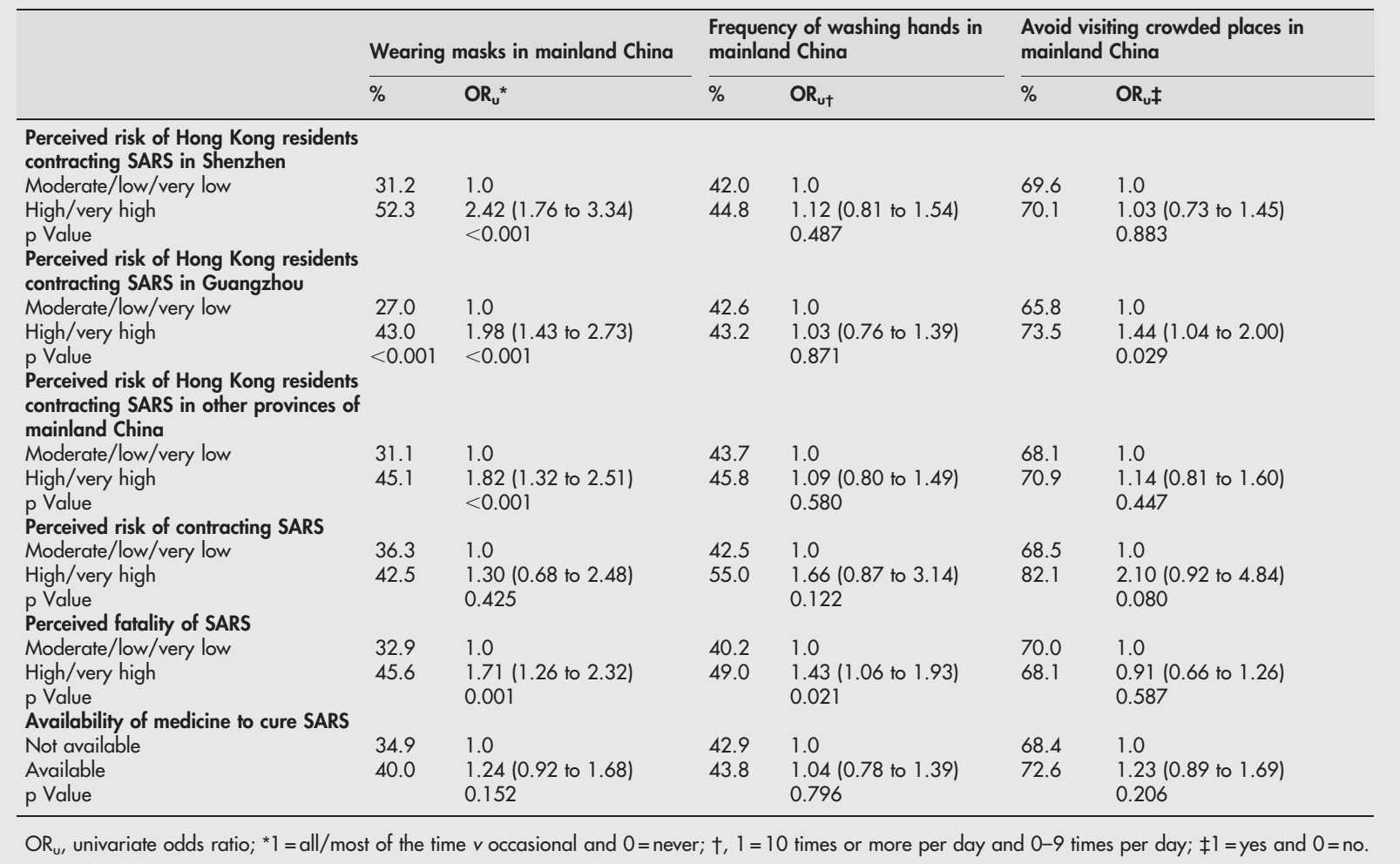

Table 3 Multivariate analysis of factors that are associated with public health behaviours for SARS prevention in mainland China

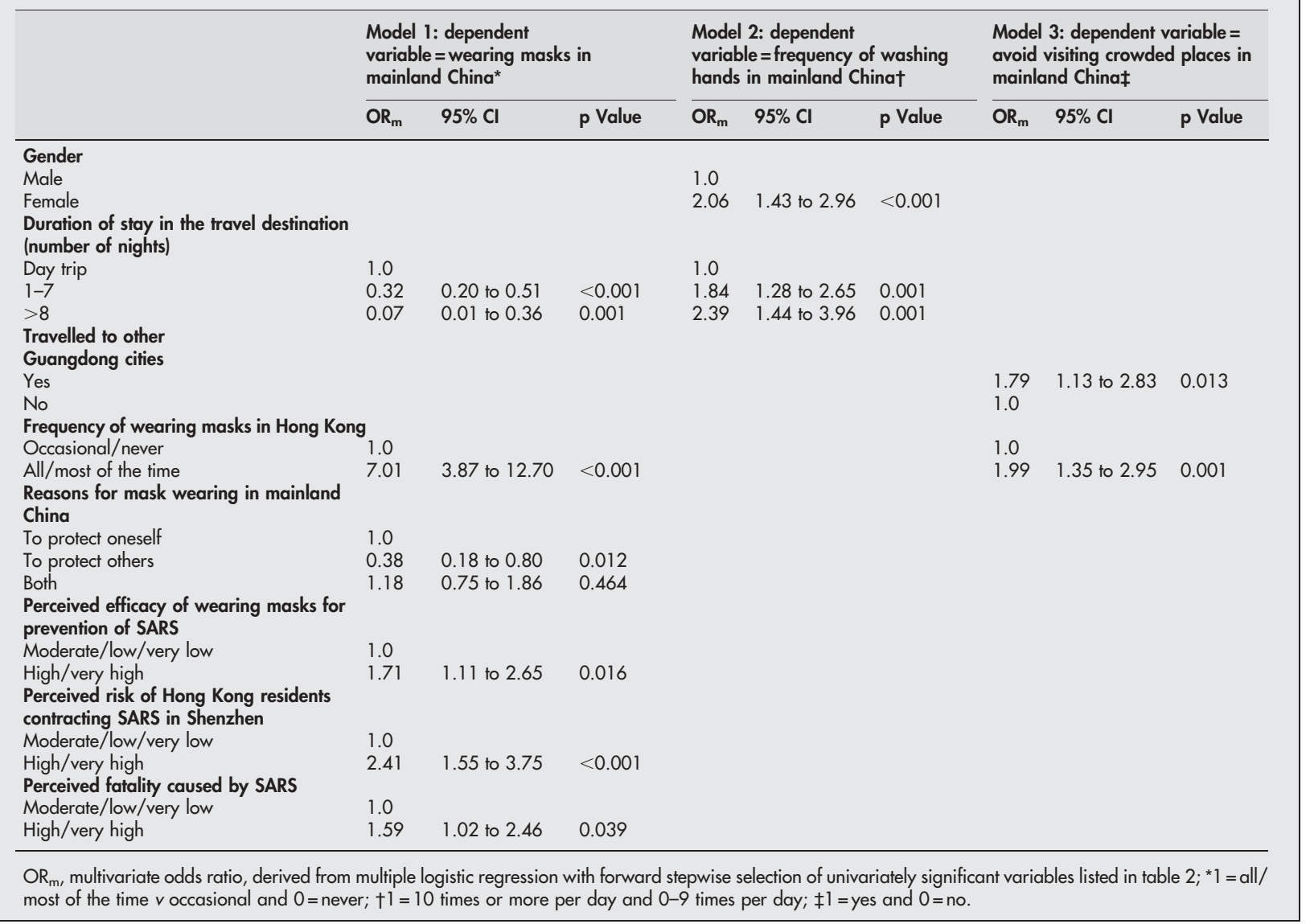


Table 4 Multivariate analysis of factors in association with perceptions and behaviours that may be conducive to the spread of SARS in mainland China

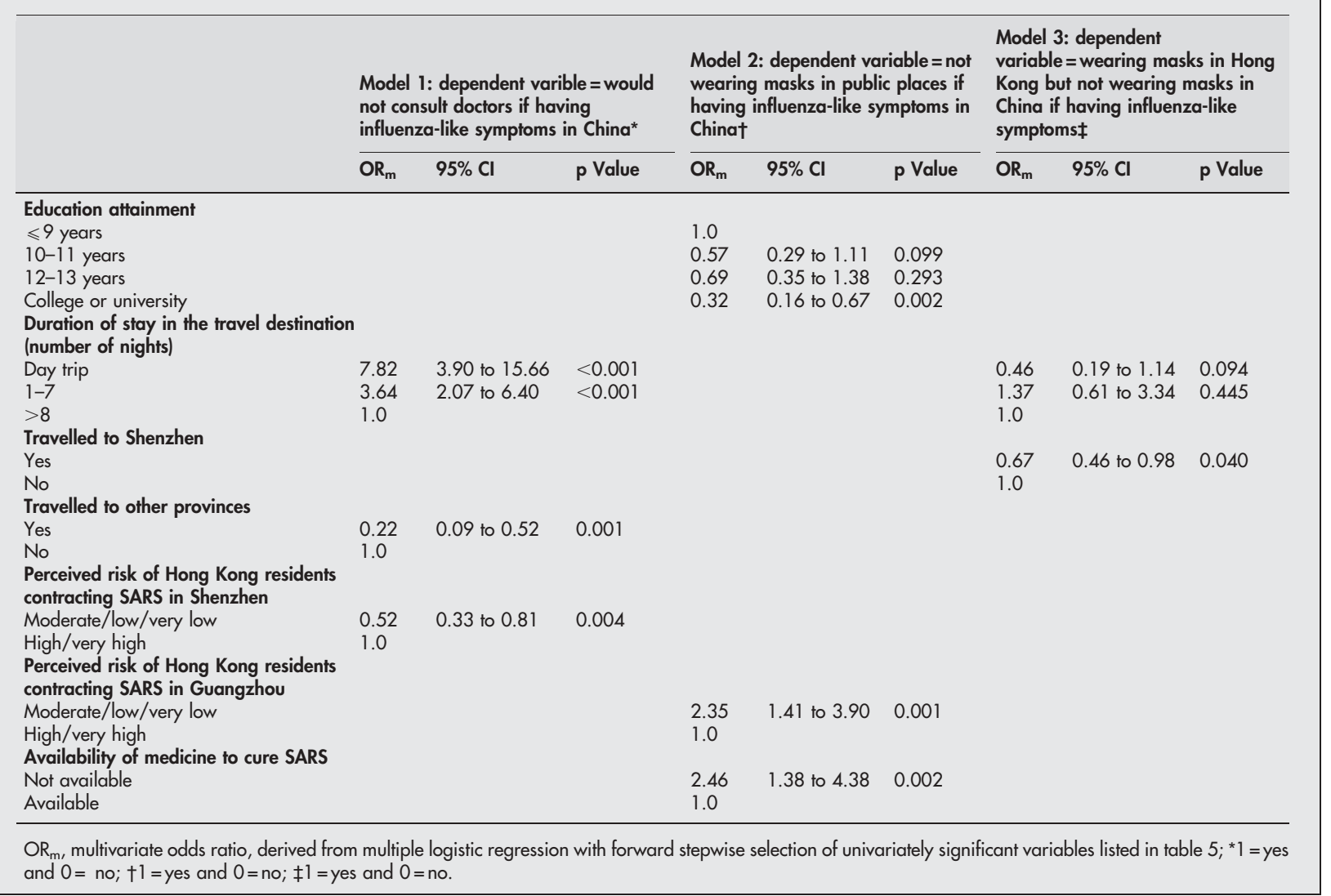

all three $\mathrm{p}$ values $<0.05)$. Almost $30 \%$ and $60 \%$ of the male and female respondents $(\mathrm{p}>0.001)$ believed that SARS was highly/very highly fatal and $64 \%$ of the male and $57 \%$ of the female respondents $(\mathrm{p}=0.143)$ that there was no available medicine to cure SARS. There were $4.3 \%$ and $8.1 \%$ of the male and female respondents respectively $(\mathrm{p}=0.048)$ believed themselves being at high/very high risk of contracting the disease.

\section{Prevalence of mask use in mainland China and associated factors}

About 37\% were wearing masks in public places all/most of the time while travelling in mainland China. Univariately, female respondents, those who were travelling to Shenzhen, those who had been always wearing masks in Hong Kong, those who perceived mask use to be highly/very highly efficacious for SARS prevention, those who perceived a high/ very high risk for Hong Kong residents to contract the virus in Shenzhen, Guangzhou or other parts in China, those believing that SARS had a high/very high fatality, were more likely than others to wear masks at their destination/s in mainland China (OR ranged from 1.48 to 10.97, p $<0.05$, table 2). Conversely, those making an overnight trip and those who wore masks for protecting others were less likely than others to wear masks in mainland China (table 2).

Multivariately, those who had been wearing masks all/ most of the time in Hong Kong in the last weeks (OR: 7.01), those who perceived high/very high efficacy of mask wearing (OR: 1.71), those who perceived a high/very high risk for Hong Kong residents to contract the virus in Shenzhen (OR: 2.41) and those who perceived that SARS was highly/very highly fatal (OR: 1.59) were more likely than others to wear masks in public places in mainland China; those making overnight trips (OR: 0.32 for one to seven nights in the mainland and OR: 0.07 for eight nights or more in the mainland) and those who used masks mainly to protect others (OR:0.38) were, however, less likely than others to use masks in public places in mainland China (table 3 ).

\section{Prevalence of frequent hand washing ( $\geqslant 10$ times/ day) and associated factors}

Overall, $43 \%$ of the respondents had been washing their hands for at least 10 times per day while they were travelling in mainland China. Univariately significant factors include longer duration of stay in mainland China, having visited Guangzhou and having perceived SARS to be high/very high fatality (table 2). Multivariately, significant factors include female gender (OR: 2.06), and longer duration of stay in mainland China (table 3 ).

\section{Prevalence of having had avoided visiting crowded places while travelling in mainland China and associated risk factors}

The results showed that $69.1 \%$ of the respondents reported having avoided visiting crowded places in mainland China (table 2). Multivariately, having visited Guangdong cities other than Shenzhen and Guangzhou (OR: 1.79, 95\% CI:1.13 to 2.83) and wearing masks in Hong Kong (all/most of the time) in the last two weeks (OR: $1.99,95 \%$ CI:1.35 to 2.95 ) were significantly associated with having avoided visiting crowded places while travelling in mainland China (table 3). Other variables, including longer duration of stay in mainland China (one to seven nights), having visited other cities in Guangdong (other than Shenzhen and Guangzhou), wearing masks all/most of the time in Hong Kong, wearing masks for the purpose of protecting both oneself and others, perception of high/very high efficacy of mask wearing for prevention of SARS, and perception of high/very high risk for 
Table 5 Perceptions and behaviours that may be conducive to the spread of SARS in mainland China (prevalence and univariate analysis)

\begin{tabular}{|c|c|c|c|c|c|c|}
\hline & \multicolumn{2}{|c|}{$\begin{array}{l}\text { Would not consult doctors if } \\
\text { having influenza-like symptoms in } \\
\text { China }\end{array}$} & \multicolumn{2}{|c|}{$\begin{array}{l}\text { Not wearing masks in public } \\
\text { places if having influenza-like } \\
\text { symptoms in China }\end{array}$} & \multicolumn{2}{|c|}{$\begin{array}{l}\text { Wearing masks in Hong Kong but } \\
\text { not wearing masks in China if } \\
\text { having influenza-like symptoms }\end{array}$} \\
\hline & $\%$ & $\mathrm{OR}_{\mathrm{u}}{ }^{*}$ & $\%$ & $\mathrm{OR}_{\mathrm{u}} \dagger$ & $\%$ & $\mathrm{OR}_{\mathrm{u}} \ddagger$ \\
\hline All & 69.3 & & 12.7 & & 32.8 & \\
\hline \multicolumn{7}{|l|}{ Gender } \\
\hline Male & 69.6 & 1.07 (0.74 to 1.55$)$ & 13.5 & $1.47(0.84$ to 2.58$)$ & 34.5 & 1.51 (1.02 to 2.23$)$ \\
\hline $\begin{array}{l}\text { Female } \\
\mathrm{p} \text { Value }\end{array}$ & 68.1 & $\begin{array}{l}1.0 \\
0.711\end{array}$ & 9.6 & $\begin{array}{l}1.0 \\
0.177\end{array}$ & 25.9 & $\begin{array}{l}1.0 \\
0.041\end{array}$ \\
\hline \multicolumn{7}{|l|}{ Age group } \\
\hline $18-29$ & 65.8 & $0.95(0.60$ to 1.51$)$ & 15.8 & 1.26 (0.68 to 2.33$)$ & 19.3 & $0.46(0.26$ to 0.79$)$ \\
\hline $30-44$ & 71.4 & $1.23(0.88$ to 1.72$)$ & 11.7 & $0.87(0.55$ to 1.42$)$ & 35.4 & 1.05 (0.75 to 1.47$)$ \\
\hline $45-60$ & 66.9 & 1.0 & 13.0 & 1.0 & 34.3 & 1.0 \\
\hline \multicolumn{7}{|l|}{ Marital status } \\
\hline Married & 70.4 & 1.01 (0.49 to 2.08$)$ & 11.7 & $0.30(0.14$ to 0.64$)$ & 35.8 & $2.23(0.96$ to 5.20$)$ \\
\hline Single & 67.5 & $0.88(0.41$ to 1.90$)$ & 12.0 & $0.31(0.14$ to 0.71$)$ & 27.5 & $1.52(0.62$ to 3.70$)$ \\
\hline $\begin{array}{l}\text { Separated/divorced/widowed } \\
\text { p Value }\end{array}$ & 70.3 & $\begin{array}{l}1.0 \\
0.755\end{array}$ & 30.6 & $\begin{array}{l}1.0 \\
0.007\end{array}$ & 20.0 & $\begin{array}{l}1.0 \\
0.033\end{array}$ \\
\hline \multicolumn{7}{|l|}{ Education attainment } \\
\hline$\leqslant 9$ years & 70.2 & 1.0 & 17.9 & 1.0 & 28.0 & 1.0 \\
\hline $10-11$ years & 75.9 & 1.34 (0.87 to 2.07 ) & 12.6 & $0.66(0.38$ to 1.14$)$ & 33.2 & 1.28 (0.83 to 1.97$)$ \\
\hline $12-13$ years & 64.9 & 0.79 (0.51 to 1.22$)$ & 13.9 & $0.74(0.42$ to 1.30$)$ & 35.0 & 1.38 (0.88 to 2.18$)$ \\
\hline College or university & 65.7 & $0.81(0.54$ to 1.22$)$ & 7.3 & 0.36 (0.20 to 0.67$)$ & 35.7 & $1.43(0.93$ to 2.19$)$ \\
\hline \multicolumn{7}{|l|}{$\begin{array}{l}\text { Duration of stay in the travel destination } \\
\text { (number of nights) }\end{array}$} \\
\hline Day trip & 85.8 & 10.00 (5.64 to 17.73$)$ & 14.6 & $0.93(0.47$ to 1.84$)$ & 16.4 & 0.52 (0.24 to 1.12 ) \\
\hline $1-7$ & 70.0 & 3.88 (2.49 to 6.04$)$ & 11.5 & $0.71(0.39$ to 1.31$)$ & 39.4 & 1.74 (0.87 to 3.45$)$ \\
\hline$>8$ & 37.6 & 1.0 & 15.5 & 1.0 & 27.3 & \\
\hline \multirow{2}{*}{\multicolumn{7}{|c|}{$\begin{array}{l}\mathrm{p} \text { Value } \\
\text { Travelled to Shenzhen }\end{array}$}} \\
\hline & & 1.46 (1.07 to 2.00$)$ & & & & \\
\hline No & 63.6 & 1.0 & 9.5 & 1.0 & 41.9 & 1.0 \\
\hline \multirow{2}{*}{\multicolumn{7}{|c|}{$\begin{array}{l}\text { p Value } \\
\text { Travelled to Guangzhou }\end{array}$}} \\
\hline & & & & & & \\
\hline Yes & 55.6 & $0.53(0.30$ to 0.93$)$ & 5.6 & $0.39(0.12$ to 1.26$)$ & 42.9 & 1.59 (0.88 to 2.85$)$ \\
\hline No & 70.2 & 1.0 & 13.2 & 1.0 & 32.1 & 1.0 \\
\hline \multirow{2}{*}{\multicolumn{7}{|c|}{ Travelled to other Guangdong cities }} \\
\hline & & & & & & \\
\hline No & 68.8 & & 13.6 & & 30.1 & $\begin{array}{l}1.01(1.15 \text { to } 2.20) \\
1.0\end{array}$ \\
\hline $\mathrm{p}$ Value & & 0.482 & & 0.218 & & 0.006 \\
\hline \multicolumn{7}{|l|}{ Travelled to other provinces } \\
\hline Yes & 24.3 & $0.13(0.06$ to 0.28$)$ & 13.5 & $1.08(0.41$ to 2.83$)$ & 44.0 & $1.64(0.73$ to 3.66$)$ \\
\hline No & 71.4 & 1.0 & 12.7 & 1.0 & 32.4 & 1.0 \\
\hline p Value & & $<0.001$ & & 0.879 & & 0.228 \\
\hline \multicolumn{7}{|l|}{ Number of trips in past month } \\
\hline 1 trip & 61.9 & $0.49(0.30$ to 0.80$)$ & 12.6 & 0.93 (0.49 to 1.78$)$ & 26.7 & 1.182 (0.69 to 2.02 ) \\
\hline $2-3$ & 67.5 & $0.63(0.39$ to 1.01$)$ & 14.1 & $1.07(0.58$ to 1.95$)$ & 34.8 & 1.74 (1.08 to 2.78$)$ \\
\hline $4-10$ & 70.3 & $0.72(0.46$ to 1.12$)$ & 11.0 & 0.80 (0.44 to 1.44$)$ & 39.7 & 2.14 (1.38 to 3.31$)$ \\
\hline$>10$ & 76.7 & 1.0 & 13.4 & 1.0 & 23.6 & \\
\hline \multirow{2}{*}{\multicolumn{7}{|c|}{$\begin{array}{l}\text { Perceived efficacy of mask wearing } \\
\text { for prevention of SARS }\end{array}$}} \\
\hline & & & & & & \\
\hline Moderate/low/very low & 70.3 & $1.21(0.87$ to 1.68$)$ & 15.2 & $2.38(1.36$ to 4.15$)$ & 33.1 & $0.97(0.70$ to 1.36$)$ \\
\hline High/very high & 66.2 & & 7.0 & & 33.8 & \\
\hline $\mathrm{p}$ Value & & 0.264 & & 0.002 & & 0.864 \\
\hline $\begin{array}{l}\text { Perceived risk of Hong Kong residents } \\
\text { contracting SARS in Shenzhen }\end{array}$ & & & & & & \\
\hline Moderate/low/very low & 66.4 & $0.56(0.39$ to 0.81$)$ & 14.0 & $1.66(0.98$ to 2.81$)$ & 35.4 & 1.48 (1.03 to 2.12 ) \\
\hline High/very high & 77.8 & 1.0 & 9.0 & 1.0 & 27.0 & 1.0 \\
\hline $\mathrm{p}$ Value & & 0.002 & & 0.060 & & 0.034 \\
\hline $\begin{array}{l}\text { Perceived risk of Hong Kong reresidents } \\
\text { contracting SARS in Guangzhou }\end{array}$ & & & & & & \\
\hline Moderate/low/very low & 61.7 & 0.59 (0.43 to 0.82$)$ & 16.3 & 2.04 (1.28 to 3.25$)$ & 33.9 & 1.02 (0.74 to 1.43 ) \\
\hline High/very high & 73.1 & & 8.7 & & 33.4 & \\
\hline $\mathrm{p}$ Value & & 0.001 & & 0.003 & & 0.891 \\
\hline $\begin{array}{l}\text { Perceived risk of Hong Kong residents } \\
\text { contracting SARS in other provinces of } \\
\text { mainland China }\end{array}$ & & & & & & \\
\hline Moderate/low/very low & 64.3 & $0.59(0.41$ to 0.83$)$ & 16.2 & 2.02 (1.22 to 3.33 ) & 35.8 & 1.33 (0.94 to 1.88$)$ \\
\hline High/very high & 75.5 & 1.0 & 8.8 & 1.0 & 29.5 & 1.0 \\
\hline $\mathrm{p}$ Value & & 0.002 & & 0.006 & & 0.102 \\
\hline Perceived risk of oneself contracting SARS & & & & & & \\
\hline Moderate/low/very low & 68.5 & $0.65(0.31$ to 1.40$)$ & 13.0 & 1.34 (0.47 to 3.85$)$ & 32.8 & 0.94 (0.47 to 1.87$)$ \\
\hline High/very high & 76.9 & 1.0 & 10.0 & 1.0 & 34.2 & 1.0 \\
\hline p Value & & 0.273 & & 0.586 & & 0.94 \\
\hline
\end{tabular}


Table 5 Continued

\begin{tabular}{|c|c|c|c|c|c|c|}
\hline & \multicolumn{2}{|c|}{$\begin{array}{l}\text { Would not consult doctors if } \\
\text { having influenza-like symptoms in } \\
\text { China }\end{array}$} & \multicolumn{2}{|c|}{$\begin{array}{l}\text { Not wearing masks in public } \\
\text { places if having influenza-like } \\
\text { symptoms in China }\end{array}$} & \multicolumn{2}{|c|}{$\begin{array}{l}\text { Wearing masks in Hong Kong but } \\
\text { not wearing masks in China if } \\
\text { having influenza-like symptoms }\end{array}$} \\
\hline & $\%$ & $\mathrm{OR}_{\mathrm{u}}{ }^{*}$ & $\%$ & $\mathrm{OR}_{\mathrm{u}} \dagger$ & $\%$ & $O R_{u} \ddagger$ \\
\hline \multicolumn{7}{|l|}{ Perceived chance of fatality caused by SARS } \\
\hline High/very high & 70.1 & 1.0 & 11.6 & 1.0 & 32.2 & 1.0 \\
\hline $\begin{array}{l}\text { p Value } \\
\text { Availability of medicine to cure SARS }\end{array}$ & & 0.727 & & 0.699 & & 0.653 \\
\hline Not available & 71.5 & 1.35 (0.99 to 1.84$)$ & 15.3 & $2.12(1.30$ to 3.46$)$ & 33.6 & $1.04(0.76$ to 1.43$)$ \\
\hline Available & 65.1 & 1.0 & 7.9 & 1.0 & 32.7 & 1.0 \\
\hline p Value & & 0.0061 & & 0.003 & & 0.803 \\
\hline
\end{tabular}

Hong Kong residents to contract SARS in Guangzhou were univariately but not multivariately significant (table 2 and table 3).

\section{Prevalence of delayed medical consultation if having influenza-like symptoms in China}

Up to $69.3 \%$ of the respondents reported that they would not see a local doctor if they were having influenza-like symptoms in mainland China, keeping in mind that the questions were asked in the middle of the epidemic. Multivariately, shorter duration of stay in mainland China was associated with a higher likelihood of delayed medical consultation (OR: 7.82 for day trip and OR: 3.64 for a one to seven night trip) (table 4). Those visiting provinces other than Guangdong and those perceiving a low risk for Hong Kong residents to contract SARS in Shenzhen were less likely than others to have delayed medical consultation, in case of having influenza-like symptoms in mainland China (OR: 0.22 and OR: 0.52, respectively). Travelling to Shenzhen during this trip and the number of trips in the past month were only univariately significant (table 5). Other factors that were not significant in both univariate and multivariate analyses.

In addition, 2.5\% (21 of 829) of the respondents reported that they actually had had influenza-like symptoms while travelling in mainland China. Among these 21 respondents,
$18(85.7 \%)$ expressed that they would have delayed medical consultation in case of having influenza-like illness while travelling in mainland China.

\section{Prevalence of mask use in public places while having} influenza-like symptoms in China

Up to $13.5 \%$ of male and $9.6 \%$ of female respondents reported that they would not wear masks in public places in mainland China, if they were having influenza-like symptoms there (table 5).

Those who believed that there was no available medicine to cure SARS, those who perceived a low risk for Hong Kong residents to contract SARS in Shenzhen were also more likely than others for not wearing masks in public places while having influenza-like symptoms in mainland China (OR: 2.46, $95 \%$ CI: 1.38 to 4.38 and OR: $2.35,95 \%$ CI: 1.41 to 3.90 , respectively) (table 4). Conversely, those who had higher education attainment were less likely to do so than their least educated counterparts (OR range: $0.32-0.57$, table 5 ).

Marital status, perceived efficacy of mask wearing for prevention of SARS, and perceived risk of Hong Kong residents to contract SARS in other provinces of mainland China were only significantly associated with wearing masks in public places in mainland China in case of having influenza-like symptoms there in the univariate analysis (table 3).

\section{Policy implications}

- During the peak of the SARS outbreak, Hong KongChina cross border travellers were practising public health measures (such as mask use and hand washing) less frequently when they were travelling in mainland China, as compared with when they were in Hong Kong, or as compared with the general population. They also tended to perceive a lower risk of contracting SARS when travelling in mainland China, as compared with the general population. For instance, about $70 \%$ of the respondents would not seek prompt medical consultation when having influenza-like symptoms while travelling in mainland China.

- A substantial proportion of respondents frequently used masks in Hong Kong, but they were not doing so in mainland China. Those who made day trips were more likely to be doing so inconsistently.

- Perceived efficacy and perceived susceptibility were significantly associated with mask use, but not hand washing.
- The attitudes and behaviours of the Hong Kong-China cross border travellers were not conducive to SARS prevention. It formed a self selective group as most of the general public would avoid visiting mainland China during the SARS outbreak.

- Special attention needs to be given to this group, which has served as a bridge population for cross border transmission of SARS. Otherwise, effectiveness of preventive programmes would be compromised and prompt detection of SARS cases among this group would be difficult. For instance, cross border medical service units may be set up.

- Labelling effects of mask wearing when travelling in mainland China also need to be addressed.

- The results of the study are relevant to prepare for the possible resurgence of SARS in this part of the world in the future. 


\section{Prevalence of wearing masks in Hong Kong but not wearing masks in mainland China}

Up to $34.5 \%$ of male respondents and $25.9 \%$ of female respondents reported that they were wearing masks in Hong Kong all/most of the time in the past two weeks but were not doing so in mainland China (inconsistent mask users) (table 5). Multivariately, those who made a day trip to mainland China were less likely than others to be inconsistent mask users (table 4). In the univariate analysis, gender, marital status, duration of the trip, location of the trip, the number of trips to mainland China in the past month, and perceived risk of Hong Kong residents contracting SARS in Shenzhen were significant only in the univariate analysis (table 5). Other perception factors listed table 5 were not statistically significant both univariately and multivariately.

\section{DISCUSSION}

The study was conducted in the middle of the outbreak of the SARS epidemic in Hong Kong. Around that same period of time, it was reported by another study that about $79 \%$ of the general public would avoid visiting mainland China and around $90 \%$ of them perceived a high/very high risk of contracting SARS when travelling in Guangdong, China. ${ }^{5}$ Therefore, worries about transmission in mainland China were very common during the study period.

A matched case-control study on SARS cases that contracted SARS from unknown sources showed that mask use and frequent hand washing were among significant protecting factors of preventing SARS transmission $\left(\mathrm{OR}=0.36\right.$ and 0.58 , respectively). ${ }^{4}$ The same study also showed that visiting China was a risk factor $(\mathrm{OR}=2.08)$. The results of this study showed that respondents were much less likely to practise SARS related preventive measures when travelling in China, when compared to prevalence of using such measures in the general population in Hong Kong. For instance, about $94 \%$ of the general public were always using face masks in public places in Hong Kong, 95\% were washing their hands frequently, and about $82 \%$ avoided visiting crowded places in Hong Kong. ${ }^{5}$ The corresponding figures were only about $37 \%, 43 \%$, and $69 \%$ respectively in this study population of cross border travellers. Furthermore, only about $28 \%$ of this sample perceived mask use to be highly/very highly efficacious in preventing SARS (almost $80 \%$ in the general population). ${ }^{5}$ Similarly, $60 \%$ compared with $32 \%$ of the two samples (general public compared with travellers) believed that SARS is fatal and $74 \%$ versus $62 \%$ respectively believed that there was no medicine to cure the disease. ${ }^{5}$ Furthermore, $90 \%$ of the general public perceived a high/very high risk of contracting SARS in Guangdong ${ }^{5}$ but only $50 \%$ or less of the travellers were having a similar perception. While almost $7.3 \%$ of the general public believed that they had a large/very large chance of contracting SARS, ${ }^{5}$ the figure was $5.0 \%$ in the traveller population (this study). It is understandable that those who were travelling to mainland China then were likely to be self selective in terms of risk perceptions. Nevertheless, this has significant bearings on SARS prevention as the above mentioned perceptions were likely to be associated with the use of preventive measures. ${ }^{5}$ It seems that travellers, on the one hand, were at risk of cross border transmission, on the other hand, their attitudes and behaviours were not conductive to effective prevention of cross border transmission of SARS. Specific prevention efforts are therefore warranted to promote SARS prevention in the traveller population. In particular, the potential effectiveness of using public health measures to reduce the risk of transmission should be emphasised.

Male travellers were much less likely to be using masks or washing their hands frequently. Promotion efforts need to take gender differences into account. Those making day trips were more likely to use face masks but interestingly, they were less likely to wash their hands frequently. Those who were making day trips may be spending much of their time outdoors and were less likely to have appropriate places to wash their hands. Hand washing during the travel should therefore be promoted as a public health measure for cross border prevention of SARS. The $\kappa$ value between the two types of preventive measures was very low $(0.046$, SE: 0.035, $\mathrm{p}=0.187)$. In other words, different forms of preventive behaviours may not always be occurring in concurrence. If the above mentioned speculation is true, contextual factors should also be considered. Pre-packed moisturised tissues with disinfecting effects may be distributed if SARS returns to this part of the world.

According to the health belief model, ${ }^{17}$ perceived susceptibility to SARS and perceived efficacy of preventive measures were likely to be associated with preventive behaviours. This turned out to be the case for mask use but not for the case of frequent hand washing. It seems to support the speculation that facilities for washing hands during their travel may be an important determinant of the behaviours.

Early detection of SARS is another important determinant of the pace and extent of the spread of SARS. The results showed that even at the peak of the SARS outbreak, delayed medical consultation was common. Firstly, Hong Kong residents may have doubts about the quality of the medical services in mainland China, and they may not be familiar with the medical services in mainland China. Hong Kong trained physicians are not allowed to practise in mainland China. Furthermore, travellers may worry a great deal about nosocomial infection. Cost and insurance may be additional hurdles for prompt medical consultation to be sought. The Hong Kong government should therefore liaise with the mainland counterparts to set up appropriate medical services in some cities that are frequently visited by Hong Kong residents.

Inconsistent mask use in Hong Kong and mainland China is another hurdle for effective SARS prevention in the traveller population. It is seen that inconsistent mask use was not associated with perception of risk of transmission in different places in mainland China, nor was its use associated with other SARS related perceptions. It was observed that the prevalence of mask use in Hong Kong was much higher than those in Shenzhen or in other Guangdong cities. It is speculated that in "a foreign place", mask use was determined not only by risk assessment, but also by the practice of the local people. Wearing masks in a place where mask use was not prevalent may create uncomfortable feelings. Mask use was much less prevalent among residents of Shenzhen and Guangzhou at the time of this study when compared with their counterparts in Hong Kong. Mask use may even create a labelling effect of being at high risk and may result in discrimination.

Hong Kong is a major international commercial hub. It is expected that more and more Hong Kong residents will visit the mainland. The Hong Kong government needs to be highly vigilant to the possible return of SARS epidemic. The observations in the middle of the epidemic do not support that the Hong Kong cross border travellers were conscious of cross border prevention of the disease. As this cross border traveller population may serve a bridge population for geographical transmission of SARS, special attention needs to be paid to this "self selected" population. Intensified health education programmes for this population are warranted. The findings are of particular relevance as new SARS cases have already reported in the Guangdong province, mainland China, which is contiguous to Hong Kong. Related experience learnt from this study is useful and 
important to prevent cross border transmissions, which might lead to another outbreak of SARS.

\section{Authors' affiliations}

J T F Lau, X Yang, $\mathrm{H}$ Y Tsui, E Pang, Centre for Epidemiology and Biostatistics, School of Public Health, Faculty of Medicine, The Chinese University of Hong Kong, Hong Kong, China

Funding: the Chinese University of Hong Kong.

Conflicts of interest: none declared.

\section{REFERENCES}

1 World Health Organisation. Summary table of SARS cases by country, 1 November 2002-7 August 2003. http://www.who.int/csr/sars/country/ 2003_08_15/en/ (accessed 15 Sep 2003).

2 World Health Organisation. Severe acute respiratory syndrome (SARS) multicountry outbreak-update 5. http://www.who.int/csr/don/2003_03_20/en/ (accessed 9 May 2003).

3 Guan $Y$, Zheng $B J, H e Y Q$, et al. Isolation and characterization of viruses related to the SARS coronavirus from animals in Southern China. Science 2003;302:276-8.

4 Lau JTF, Tsui $H$, Lau M, et al. SARS transmission, risk factors, and prevention in Hong Kong. Emerg Infect Dis 2004:10:587-92.

5 Lau JTF, Yang X, Tsui HY, et al. Monitoring community responses to the SARS epidemic in Hong Kong - from day 10 to day 62. I Epidemiol Community Health 2003;57:864-70

6 Hong Kong Government Information Centre. Hong Kong residents departures by destination. http://www.info.gov.hk/censtatd/eng/hkstat/ hkinf/transport/transport_index.html (accessed 27 May 2003).
7 Hong Kong Government Information Centre. Visitor arrivals by country/ territory of residence. http://www.info.gov.hk/censtatd/eng/hkstat/hkinf/ transport/transpl 1_index.html (accessed 15 Sep 2003)

8 Hong Kong Tourism Board. Surge to $1.64 \mathrm{~m}$ visitors arrivals in August brings return to positive growth. http://partnernet.hktourismboard.com/pnweb/jsp/ $\mathrm{comm} /$ index.jsp? pageContent $=/$ isp $/ \mathrm{rso} / \mathrm{rso}$ _news. jsp\&charset $=$ en (accessed on 13 Oct 2003).

9 World Health Organisation. New case of laboratory-confirmed SARS in Guangdong, China-update 5. http://www.who.int/csr/don/2004_01_31/ en/ (accessed 3 Feb 2004).

10 Riley S, Fraser C, Donnelly CA, et al. Transmission dynamics of the etiological agent of SARS in Hong Kong: impact of public health interventions. Science 2003;300:1961-6.

11 Lau JT, Thomas J. Risk behaviours of Hong Kong male residents travelling to mainland China: a potential bridge population for HIV infection. AIDS Care $2001 ; 13: 71-81$.

12 Lau JT, Wong WS. Behavioural surveillance of sexually-related risk behaviours for the cross-border traveller population in Hong Kong: the evaluation of the overall effectiveness of relevant prevention programmes by comparing the results of two surveillance surveys. Int J STD AIDS 2000;11:719-27.

13 Lee N, Hui D, Wu A, et al. A major outbreak of severe acute respiratory syndrome in Hong Kong. N Engl J Med 2003;348:1986-94.

14 World Health Organisation. Cumulative number of reported probable cases of SARS. http://www.who.int/csr/sars/country/2003_07_09/en/ (accessed 29 Jul 2003).

15 World Health Organisation. Update 17-travel advice-Hong Kong Special Administrative Region of China, and Guangdong Province, China. http:// www.who.int/csr/sars/archive/2003 $0402 / \mathrm{en} /$ /accessed on $29 \mathrm{Jul}$ 2003).

16 World Health Organisation. World Health Organisation changes Hong Kong, Guangdong travel recommendations. http://www.who.int/ mediacentre/releases/2003/prwha4/en/ (accessed on 29 Jul 2003).

17 Fisher JD, Fisher WA. Theoretical approaches to individual-level change in HIV risk behavior. New York: KluwerAcademic/Plenum, 2000.

POEM

\section{Lead free}

evi Tafari can be viewed performing this poem on the JECH web site at: http:// www.jech.com/misc/poems.shtml with children from Windsor Street School in Liverpool, UK. The Editors would like to thank Windsor Street School and National Museums Liverpool (http://www.liverpoolmuseums.org.uk) for their help with the filming of this performance.

I want to write a poem to express the way I feel but the EARTH is inna very sad state and this time it's for real

I cannot write this poem because of western culture

which has used up most of the EARTH'S resources and put her under pressure

Minerals don't exist no more

there's no solution

there is no cure

And now it seems an impossibility

to finish this piece of poetry

do you know what is restricting me?

the pencil I am holding is LEAD FREE!

\section{ACKNOWLEDGEMENTS}

This poem was originally published in Tafari L. Rhyme Don't Pay. Wirral, UK: Headland Publications, 1993 (available from Headland Publications at 38 York Avenue, West Kirby, Wirral CH48 3JF), and is reproduced in the $J E C H$ with the author's permission. 